\title{
Wildlife tracking with latest electronic technology
}

\begin{abstract}
Since a protracted durable the tightlipped animals are studied by man, creating use of the many a method. Of course, within the starting it had been the employment of the fundamental explanation that helped them study animals. Folks would watch them, follow their tracks, creating interpretations etc. Those were the times of the co-existence for man and animal. The diversity of the kingdom is exploited so as that each little and enormous animals is tracked and monitored victimization constant system. ${ }^{1}$ Application of geoinformatics (remote sensing, Geographic system (GIS) associate degreed GPS) has enjoying an progressively vital role in conservation biology and life management by providing means that for grouping point and habitats data of life. Another advantage of the system is that the facility to integrate non-spatial knowledge directly, purpose knowledge collected from the sphere, GPS knowledge of life observance, pugmarks, scats, pellets etc. are fed directly and might generate a separate layer. But the trendy research goes on the far side the radio signals. It helps researchers to urge additional precise answers to the targeted queries concerning environs, migration patterns among others. And these answers are quantitative and analytical. Also, the advancement in technology has helped scientists to try to analysis victimization additional non-invasive means that and besides create the invasive ways safer. Each time a GPS radio collars tries to record a location it records data on the date, time and latitude. This data is then utilized to calculate the gap between locations, travel speed, location methods, direction, daily activity levels, home ranges, and analysis of spatial and temporal variations in behavior.
\end{abstract}

Keywords: satellite telemetry, animal tags, positioning
Volume 3 Issue 3 - 2018

\author{
Jorawar Singh, Basant Bais \\ Rajasthan University of Veterinary and Animal Sciences, India
}

Correspondence: Basant Bais, Department of Livestock Products Technology, College of Veterinary and Animal Sciences, Rajasthan University of Veterinary and Animal Sciences, Bikaner, Rajasthan, 33400I, India, Email basantbais@gmail.com

Received: May 25, 2018 | Published: June 12, 2018

\section{Technologies for tracking}

Recent technologies have helped solve the matter of untamed life following. Some electronic tags provide off signals that are picked up by radio devices or satellites whereas alternative electronic tags may embody deposit tags. ${ }^{2}$ Scientists will track the movement and locations of the labeled animals. These electronic tags will offer a good deal of information. Also, owing to their size and weight, electronic tags could produce drag on some animals, fastness them down. However, they're costlier than the low-tech tags that are not electronic.

\section{Radio tracking}

Tracking an animal by radio involves 2 devices. A VHF receiver picks up the signal, a bit like a home radio picks up a station's signal. The receiver is sometimes during a truck, an ATV, or an airplane. To stay track of the signal, the soul follows the animal victimization the receiver. A transmitter attached to the animals sends out a proof within the type of radio waves, even as a radio station does. ${ }^{3}$ A soul would possibly place the transmitter around associate degree animal's ankle, neck, wing, carapace, or dorsal fin. This approach of victimization radio following is accustomed track the animal manually however is additionally used once animals are equipped with alternative payloads. ${ }^{4,5}$

\section{Satellite tracking}

Networks, or groups, of satellites are accustomed track animals. Every satellite network picks up electronic signals from a transmitter on an animal. A receiver is placed in Earth-orbiting satellites like ARGOS. Together, the signals from all satellites verify the precise location of the animal. The satellites conjointly track the animal's path because it moves. Satellite-received transmitters fitted to animals also can offer data concerning the animals' physiological characteristics e.g. temperature. Satellite networks have tracked the migration and territorial movements of deer, ocean turtles, whales, nice white sharks, seals, elephants, bald eagles, ospreys and vultures. In addition pop-up satellite tags are used on marine mammals and varied species of fish. ${ }^{6}$ Satellite following is particularly helpful as a result of the scientists ought not to follow when the animal nor do they need to recover the tag to urge the info on wherever the animal goes or has gone. There are 2 main systems, the on top of mentioned Argos and the GPS. ${ }^{7}$

\section{Global positioning systems}

Global Positioning Systems (GPS) are therefore common in everyday life; currently it's few surprise that the technology is additionally employed in life following. GPS may be a evidenced technology; there are variety of terribly pricey satellites in orbit over the planet, that regularly send signals that GPS receivers will receive. ${ }^{8}$ It's been significantly helpful in observation marine mammals and fish species, that travel long distances and pay time underwater, creating alternative varieties of following troublesome. To make GPS easier to use, the line of longitude and latitude is displayed over a map which can show piece of ground options, roads, streets and even specific addresses. Supported the info from the satellite signal, a GPS receiver calculates its own location and displays that location for the user.

Totally different form of GPS devices are used for following of life animals:-

\section{GPS/Argos:-}

GPS-location acquisition

Argos satellite system-remote knowledge transfer.

GPS/Iridium:-

GPS-location acquisition.

Iridium satellite system-remote knowledge transfer. 
GPS/Global star:-

GPS-location acquisition

Global star satellite system-remote knowledge transfer.

GPS/geostationary (GEO):-

GPS-location acquisition

Geostationary satellite system-remote knowledge transfer.

GPS/global system for mobile communications (GSM):-

GPS-location acquisition

Cellular network-remote knowledge transfer.

GPS/store on board (SOB), VHF or ultra-high frequency (UHF):device

GPS-location acquisition, storing the locations on the following

AVH for UHF receiver-transfer the info manually within the field.

GPS/SOB drop-off

GPS/SOB recapture

There are tons basic examples wherever GPS will facilitate enforcement officers:

Location identification: GPS helps to suggests and conserving data this specific location in memory on the device.

Preventing illicit activities: A marine or life officer could use GPS technology to find and publish a hide wherever folks try to or are within the method of searching illicitly. The officers will use GPS technology to document specifically wherever it's as a result of an address won't be offered. Another sensible state of affairs could also be that the officers get into the woods and are available across criminal activity like a marijuana field or a chalk laboratory. The GPS device can bear in mind the placement and can show the info afterward and might determine spatial patterns of alternative illicit activities.

Wild animal following: The technology is accustomed determine trends over each time, space, and climatic conditions, assist following of the movement of untamed animals, prepare spatial maps of forests, and even facilitate cut back cookery.

The police time interval to distress calls can improve by combining the Geographical system (GIS) and GPS within the main room, a number of the advanced uses of GPS for enforcement are:

Tracking people/vehicles: law social control officers will take a GPS receiver and covertly attach it to a vehicle. It calculates its location and remembers it. That knowledge is recorded and so afterward the officers will transfer the knowledge from the device, place it on a pc and show once and wherever the vehicle was. The receiver is ready up to at specific, pre-set, pre-determined intervals. It will even show a vehicles specific route and speed.

Live tracking: More advanced GPS gadgets can at once translate the placement through a cellular phone on another wireless affiliation and officers will stand back and live track the vehicle either through a laptop computer that receives a cellular phone signal.

Faster and coordinated response: This can change correct and period observation and following of their armed service, taking time interval to associate degree emergency to an entire new level of potency. A state of affairs wherever a decision is received at the police room, the knowledge is instantly routed to the primary offered officer on duty whiles, virtually at the same time, a info begins a pursuit to seek out the address related to the amount. The hold for the complete sequence of events might not be over ten seconds until the identification of the placement of the caller, and one minute until the distribution of the case.

\section{Digital remote cameras}

To monitor species is to use remote-activated camera traps. The "shots" offer monitors and researchers with fantastic data-permitting them to assess the standing of species on a reserve and to assist develop and monitor management interventions. These are basically remotely activated moveable cameras that are triggered by motion through infrared or a motion sensing element. ${ }^{9}$

Camera traps is used for various applications: Whether or not its observation population sizes or to answer a selected analysis question. In Africa specifically, camera traps still be a crucial part of species observation, significantly for additional elusive species like leopard and black rhinoceros. Once used effectively, the knowledge captured by camera traps is valuable-particularly once let alone alternative observation techniques. The popularity of nest box cameras for grounds use had its beginnings in life analysis. In several are as these animals are characteristically back and troublesome to watch, which may end in poor data of a population and its demographics and ultimately poor population management. The power to watch nesting birds while not disturbance greatly increased data of craniate development. Today, cellular phone cameras arouse to supply the photographs in real time to remote observers.

\section{Rhino ankle collars}

Animal Trackem (a radio following company) are planning, testing and deploying rhinoceros mortise joint collars.In the past, neck collars are used however unsuccessfully. before rhinoceros mortise joint collars, the sole productive radio following device that may be deployed on a rhinoceros may be a horn implant. ${ }^{10}$ These collars are a reasonably new invention because of size limitations, these rhinoceros horn transmitters are solely sufficiently big for a VHF radio following device. Although there's still area for improvement, these collars are operating well, and have provided America with valuable movement knowledge, that conjointly assists in securing these rhinoceros. The advantage of the rhinoceros mortise joint collar is that it permits for a much bigger battery and device-permitting America to suit GSM (cell phone) and Satellite units to rhinoceros. Some collars are reportage live to our management rooms that improve security efforts dramatically. ${ }^{11}$

\section{Very high frequency (VHF)}

The first with success tested system was incontestable in 1963. This technology was the earliest modality used for following and distinctive individual wild animals electronically. A VHF following system consists of 2 parts-the transmitter (mounted on the animal) and therefore the remote receiver.

\section{Cape may bird observatory}

Tracking data is employed to check the migration patterns of monarchs, together with however so much and wherever they fly. The Observatory is one amongst the organization that incorporates a monarch identification tagging program. Plastic stickers are placed on the wing of the insect with identification data. ${ }^{12}$ 


\section{Cell phone technology accustomed track migration}

The ability to follow little songbirds had been restricted by the dimensions of the instrumentality the birds would want to hold. All those cellular phone towers place in situ to reinforce human communication are currently being utilized in following migratory animals. Miniaturized units have become terribly cheap and with the amount of cellular phone towers that exist worldwide there'll be fewer and fewer gaps in knowledge.

\section{Digital camera binoculars}

Binoculars allowto see specific details (e.g., colors, beak shapes, etc.) that may greatly aid within the identification of unknown species. Binoculars provide the identification of animals that may somewhat be to distant or troublesome to envision.

\section{Light-level geo location (non-satellite)}

A comparison of the 2 parameters is employed for location calculation. A deposit tag is capable of storing knowledge on lightweight-intensity levels (sunrise and sunset times) and activity the present light levels. The locations are obtained by retrieving the deposit tag and downloading the info manually.

\section{Field guides}

Field guides for distinctive birds, mammals, and tracks, and even scat singing are particularly valuable once observation life and are a good thanks to involve children too.

\section{Track plates}

When in high traffic areas, track plates will offer proof of passing animals which may not somewhat be captured. Track plates are devices that use chalk, sand or alternative materials to create impressions or prints of animal tracks.

\section{Trail cameras}

Most path cameras allowto got wind of the amount of photos which will be taken promptly. Trail cameras are rug-ged units that run on batteries and might be placed on trees, fence posts or alternative objects and left to require photos on their own once triggered by movement. Check path cameras frequently to transfer digital files and replace batteries.

\section{Conclusion}

Radio systems capable of localization have rising applications in Office of Homeland Security, enforcement, emergency response, defense command and management, multi-robot coordination and vehicle-to-vehicle and vehicle-to-pedestrian collision turning away. Life following victimization wireless networks has become recently doable because of the increasingminiaturization of electronic technology. This has allowed life following collars to make multihop networks to transfer data from the sphere to the end-user. In fact, high resolution localization is important for several applications, including: traffic alert, emergency services, e.g., indoor localization for firefighters, and piece of land command and management. Would like of data in conservation of life essentially involve characterizing the placement, home range, activity patterns and standing of the forest resources and its amendment in spatial and time domain. These systems promise to dramatically cut back society's vulnerabilities to ruinous events and improve its quality of life. Whereas work this vital space is progressing, restricted resources are offered to support graduate students and researchers during this vital space. This is often a brand new method of having the ability to trace and monitor animals mechanically. Howeverresearch up to now has focused on instrumenting one species of interest, resultingin a consistent (single tag design) answer. Zebra Net and Turtle Net placed GPS enabled wireless devices on zebras and turtles severally. However, in each Zebra Net and Turtle Net, only 1 form of device was designed. However, their devices are onlysuitable for attachment to larger animals, so limiting their preparation scope to a section of the kingdom.

\section{Acknowledgements}

None.

\section{Conflict of interest}

The Author declares that there is no conflict of interest.

\section{References}

1. Cargnelutti B, Coulon A, Hewison AJ, et al. Testing world positioning system performance for life observation victimisation mobile collars and renowned reference points. The Journal of life Management seventy one. 2007;(4):1380-1387.

2. Patric Earl F, Shaughnessy Gail A, Will Gary B. A listing of life measuring and Radio Tracking: Department of Forest and life Management, school of Resource Development. Island: University of Rhode Island; 1982.

3. Aebischer NJ, Robertson PA, Kenward RE. Compositional analysis of environs use from animal radio-tracking knowledge. Ecology. 1993;(74):1313-1325.

4. Cochran WW, Lord Rexford T. A radio-tracking system for wild animals. The Journal of Wildlife Management twenty seven. 1963;28(1):42-45.

5. Cagnacci F, Boitani L, Powell RA, et al. Animal ecology meets GPSbased radio telemetry: an ideal storm of opportunities and challenges. Philosophical Transactions of the honorary society. Philos Trans $R$ Soc Lond B Biol Sci. 2010;365(1550):2157-2162.

6. Cohn JP. Following wildlife: sophisticated devices facilitate biologists trace the movements of animals through sky and ocean. Life science forty nine; 1999. p. 12-17.

7. Witt MJ, Akesson S, Broderick AC, et al. Assessing accuracy and utility of satellite-tracking data using Argos-linked Fastloc-GPS. Animal Behaviour. 2010;80:571-581.

8. Tomkiewicz. Tracking of Wild Life: A Convergence of Technologies. Telonics; 1996.

9. Garshel, David L, Quigley, et al. Assessment of telemetric motion sensors for studies of activity. Canadian Journal of Zoology. 1982;60(8): 1800 1805 .

10. Tomkiewicz, Stanley. Advances in Satellite and Radio Location Technology. Conferred at the Eleventh Annual data Transfer Meeting of Mineral Management Service's Gulf of North American nation OCS Region in point of entry; 1990.

11. Villepique JT, Bleich VC, Pierce BM, et al. Evaluating GPS collar error: a critical evaluation of Televilt POSREC-Science TM collars and a method for screening location data. California Fish and Game. 2008;(94):155168.

12. Bridge ES, Kelly JF, Contina A, et al. Advances in tracking small migratory birds: a technical review of light-level geo location. Journal of Field Ornithology. 2013;84:121-137. 